\title{
PELUANG DAN TANTANGAN DALAM MENGIMPLEMENTASIKAN SISTEM MANAJEMEN DOKUMEN ELEKTRONIK (SMDE)
}

\author{
Lasmita Sihaloho, Ade Sobandi \\ Universitas Pendidikan Indonesia (UPI) \\ (lasmita_sihaloho@student.upi.edu,ade@upi.edu)
}

\section{INTISARI}

Seiring dengan bertambahnya jumlah dokumen yang harus disimpan secara terus-menerus serta banyaknya kegiatan organisasi yang berkaitan dengan dokumen, maka setiap organisasi dituntut untuk dapat mengelola dokumen atau kearsipannya dengan memanfaatkan teknologi dan informasi (TI), salah satunya adalah dengan mengimplementasikan sistem manajemen dokumen elektronik (SMDE). Tujuan penelitian ini adalah untuk mendeskripsikan peluang dan tantangan dalam mengimplementasikan sistem manajemen dokumen elektronik (SMDE) dalam dunia pendidikan, pemerintahan dan dunia usaha. Metode penelitian yang digunakan adalah kajian eksploratif dengan kombinasi tinjauan pustaka. Data penelitian diperoleh berdasarkan hasil kajian dari beberapa sumber literatur pustaka sebagai bahan acuan yang berhubungan dengan masalah yang diteliti. Hasil penelitian menunjukkan bahwa kajian sistem manajemen dokumen elektronik (SMDE) dalam dunia pendidikan, lembaga pemerintahan serta dunia usaha memiliki peluang dan tantangannya masing-masing dalam mengimplementasikan SMDE sesuai dengan tuntutan kerja dalam pengelolaan dokumen, oleh karena itu diperlukan dukungan dan kerjasama baik secara internal maupun eksternal organisasi dalam mengatasi tantangan pengelolaan dokumen yang ada sehingga manfaat SMDE dapat dirasakan secara efektif dan efisien.

Kata Kunci: dokumen elektronik (SMDE), ISO9001, ISO9004, manajemen dokumen, sistem manajemen.

\section{ABSTRACT}

Along with the increasing number of documents that must be stored continuously and the many of the organization's interests relating to documents, then every organization is required to be able to manage documents or archives by utilizing information and technology (IT). One of which is by applying the electronic document management system(EDMS). The purpose of this research is to describe opportunities and Challenges in Implementing Electronic Document Management Systems (EDMS) in education, government and business. The research method is explorative with combination literature review. The data of this Research is obtained based on the results of studies from several sources literature as a reference material that is associated with the problem under research.The research results show that electronic document management system (EDMS) in education, government, and business have their own opportunities and challenges in implementing EDMS, therefore the need for support and cooperation both internally and externally organizations in overcoming the document management challenges so that the benefits of SMDE can be felt effectively and efficiently.

Keywords: document management, electronic document management system (EDMS), ISO9001,ISO9004. 


\section{PENGANTAR}

\section{Latar Belakang Masalah}

Dokumen menjadi salah satu hal yang penting dalam suatu kegiatan baik di dalam perusahaan, lembaga atau organisasi karena di dalam dokumen banyak terdapat informasi penting yang menyangkut banyak hal termasuk perencanaan kegiatan, pengambilan keputusan, penyusunan kebijakan, pengawasan kinerja, evaluasi kebijakan, dan lain-lain. Seri ISO9001 adalah standar internasional manajemen mutu dan jaminan kualitas. Ini menggambarkan kualitas dokumen dan data kontrol persyaratan sistem termasuk persetujuan, pengeluaran, pengaksesan dan pengubahan dokumen atau arsip (ISO9001, 2015). Ini juga menyatakan bahwa perusahaan harus menetapkan tata cara untuk membuat modifikasi, revisi, dan penambahan isi dokumen (ISO9004, 2016) akan tetapi dalam kenyataannya banyak organisasi, lembaga dan perusahaan yang belum mengelola dokumennya sesuai dengan ketentuan seri ISO9001 dan ISO9004 sebagai standar yang berlaku. Yao \& Trappey (2001:355) dalam Finney (1999) melaporkan bahwa masalah utama yang berkaitan dengan pengelolaan dokumen adalah ketidaksesuaian dengan ketentuan ISO9001.

Penggunaan dokumen memerlukan sistem yang dapat mengelola dokumen secara efektif dan efisien agar dapat dipakai pada waktu tertentu sesuai dengan fungsinya, salah satunya adalah melalui Elektronic Document Management System (EDMS). Hal ini sesuai dengan pendapat (Simonds, 2008:22) bahwa penggunaan Document Management System (DMS) merupakan repository yang digunakan untuk menyimpan, mengatur dan melacak dokumen. Keuntungan dari DMS ini adalah pengurangan redudansi dokumen pada sistem. Document management adalah key enabler dalam proses knowledge management (KM). KM berfokus dalam mengumpulkan, menyimpan dan membagikan informasi; Penggunaan DMS sangat berperan penting dalam memastikan bahwa informasi itu tersedia. Menurut (Adam, 2007:8) penggunaan media baru seperti komputer dan alat-alat elektronik lainnya juga mendorong adanya sistem pengelolaan dokumen elektronik atau disebut dengan Electronic Document Management System (EDMS).

Dalam rangka menghindari dan memastikan masalah yang dihadapi pada penggunaan tahap awal, maka manfaat EDMS perlu diintegrasikan sesuai dengan kebutuhan. Pendekatan terencana dan partisipasi semua pihakharus dilakukan sejalan dengan penerapan dan penggunaannya, karena EDMS diperkenalkan melalui komitmen positif untuk pengelolaan dokumen secara teratur oleh penggunanya (Robson, 2010 dalam Jones, 2012: 397). Implemetasi EDMS harus memastikan bahwa teknologi baru harus dapat memenuhi kebutuhan dan persetujuan penggunanya, karena beberapa fakta dari penelitian yang ada telah menunjukkan bahwa penerapan EDMS tidak mudah tercapai atau dipahami dengan baik (Remenyi, Bannister, \& Money, 2007:275).

\section{Rumusan Masalah}

Melihat perkembangan teknologi informasi yang sangat pesat dan tingginya produksi dokumen dalam bentuk elektronik maka menjadi 
sangat penting untuk mengkaji bagaimana implementasi EDMS dalam pemerintahan, dunia pendidikan dan dunia usaha.

\section{Tujuan Penelitian}

Tujuan penelitian ini adalah untuk mendeskripsikan peluang dan tantangan dalam mengimplementasikan sistem manajemen dokumen elektronik (SMDE) dalam dunia pendidikan, pemerintahan dan dunia usaha.

\section{Metodologi Penelitian}

Penelitian ini merupakan kajian eksploratif dengan kombinasi metode tinjauan pustaka yang mencoba memaparkan fenomena yang ada dalam mengahadapi peluang dan tantangan dengan menerapkan sistem manajemen dokumen elektronik (SMDE) atau EDMS sesuai dengan kaidah teori yang berlaku. Data sekunder dari literatur-literatur dan sumber-sumber tertulis lainnya yang berhubungan dengan masalah yang akan diteliti. Hasil dari penelitian selanjutnya di interprestasikan secara deskriptif.

\section{Kerangka Pemikiran}

Perubahan pengelolaan arsip dari kertas (paper-based) menuju digital dimaksudkan menggantikan struktur birokrasi dan administratif yang kaku menjadi sistem administrasi publik yang lebih fleksibel, efektif, dan efisien dalam suatu institusi (Asogwa, 2012:200 dalam Putranto, 2017:4). Dengan penggunaan dan kenyamanan internet seperti sekarang yang sudah sedemikian melekat dalam kehidupan sehari-hari masyarakat, respon pengelolaan arsip terhadap tren terbaru seharusnya mampu memberikan sumbangsih sosial yang penting, seperti berpartisipasi dalam peningkatan kualitas layanan dan kebijakan publik dengan memanfaatkan teknologi jejaring sosial (Harries, 2009:18, dalam Putranto, 2017:4).

Secara umum, institusi pengelola dokumen dan informasi sedang melakukan transisi pengelolaan dari paper-based menuju pengelolaan berbasis elektronik. Transisi ini tidak dapat dihindarkan dikarenakan arsip fisik memiliki sejumlah keterbatasan yang menghambat kebutuhan untuk menyesuaikan tuntutan atas kecepatan informasi pada saat ini (Wilkins et al, 2009:40 dalam Putranto, 2017:5). Hal tersebut kerap kali menjadi kompleks dengan banyak aturan dan kebijakan institusi sebelumnya yang bersifat paper based (Reed, 2010:125 dalam Putranto, 2017:5) sehingga implementasi secara bertahap dan transisi yang dilakukan institusi harus menyesuaikan budaya record keeping yang ada (Gregory, 2005:80 dalam Putranto, 2017:5).

Document management system (DMS) adalah sistem informasi yang ditujukan untuk pengelolaansiklus hidupdokumen elektronik yang merupakan periode dari ide konseptual ke logika danpemusnahan dokumen secara fisik, terdiri dari inisiasi, persiapan, penetapan, penggunaan, revisi, penarikan, dan tahap penghapusan (International Organization for Standardization (ISO), 2001) dalam(Sladić et al., 2017:803).

DMS dapat didefinisikan sebagai sistem komputer yang digunakan untuk menyimpan, melacak, dan mengambil dokumen elektronik (Zantout \& Marir, 1999:472). Electronic document management (EDM) didefinisikan 
sebagai "penerapan teknologi untuk menghemat kertas, mempercepat komunikasi, dan meningkatkan produktivitas proses bisnis" (Sprague, 1995:29). Sejak tahun 1990-an, para peneliti telah mengenali peran dasar yang dimainkan oleh Electronic Document \& RecordsManagement System (EDMS) dalam berbagai layanan pemerintah (Sprague, 1995:30).

Pengertian lainnya ERDMS (Electronic Document \& Records Management System) merupakan sebuah sistem yang digunakan untuk mengelola arsip dan dokumen elektronik. Definisi ERDMS secara lengkap diungkapkan National Archives of Australia (2005) sebagai sebuah sistem otomasi yang digunakan untuk mendukung akuisisi, penggunaan dan pemeliharaan dokumen secara elektronik yang dibuat untuk mencapai tujuan organisasi (Johnston \& Bowen, 2005:132).

Tujuan EDMS adalah mengelola dan mengendalikan semua dokumen dalam perangkat elektronik baik dokumen pengolah kata, spreadsheet, presentasi, grafik atau pesan email, dan lain-lain sesuai dengan fungsinya (Groenewald, 2004:54). Adapun manfaat utama EDMS menurut (Adam, 2007:205) dirangkum sebagai berikut:

1. Staf yang menghadapi pelanggan memiliki akses terhadap informasi yang mereka butuhkan untuk memberikan pelayanan yang lengkap;

2. Jika dikombinasikan dengan ponsel, maka lebih fleksibel dan dapat bekerja di rumah, staf dapat mengakses informasi tersebut dimanapun mereka berada;
3. Memegang informasi secara elektronik yang berarti bahwa dokumen kertas yang asli dapat dihancurkan, sangat mengurangi kebutuhan pengarsipan ruang di kantor;

4. Sekitar $20 \%$ ruang kantor menjadi bebas dengan menyimpan informasi secara elektronik dan bukan di kertas;

5. Mengurangi pencetakan dan printer, karena dokumen dipegang secara elektronik;

6. Penghematan secara efisiensi yang signifikan dapat dicapai, sehingga mengurangi jumlah staf;

7. Memberikan jejak audit atas pembaruan informasi elektronik; dan

8. Meningkatkan manajemen informasi.

Keuntungan menerapkan ERDMS pada organisasi yang bergerak di bidang kearsipan dibagi menjadi 3 menurut (Johnston \& Bowen, 2005:134) yaitu:

1) Untuk pengguna individu: informasi yang diperlukan tersedia, pekerjaan menjadi lebih efektif dan efisien, meminimalisir kesalahpahaman dan rasa curiga antar pegawai, dan tersedia bukti pekerjaan yang ketika diminta;

2) Untuk organisasi: pekerjaan selesai lebih cepat, penyelesaian tugas dilakukan dengan mudah, adanya peningkatan kualitas proses dan hasil kerja, peningkatan kas, dan meningkatkan kesadaran dan kepatuhan terhadap hukum dan peraturan; dan

3) Untuk masyarakat secara keseluruhan: proses organisasi yang terbuka dapat dipahami dan dimonitor oleh masyarakat pengguna, organisasi mematuhi hukum dan 
peraturan, adanya peningkatan kualitas kehidupan, dan catatan sejarah dapat diakses dengan mudah.

\section{PEMBAHASAN}

Penggunaan EDMS yang efektif merupakan elemen penting dalam membangun lingkungan tempat kerjadan mengubah kemampuan organisasi modern dan angkatan kerjanya (Adam, 2007:41). Efisiensi operasional dapat berubah melalui penerapan Information and Technology (IT) sesuai fungsi Back office terutama pada implementasi EDMS (Read, 2009 dalam Jones, 2012:396). Implementasi EDMS dalam beberapa studi kasus menurut literatur, membuat perbedaan yang signifikan terhadap efisiensi dari otoritas lembaga yang menawarkan manfaat dan keuntungannya (Adam, 2007:43). EDMS banyak diperkenalkan dalam 2-3 tahun terakhir (Robson, 2010 dalam Jones, 2012:398).

EDMS diperlukan untuk mendukung perubahan yang signifikan terhadap cara organisasi melaksanakan tanggung jawab kerjanya untuk jangka panjang di tahun-tahun depan yang akan datang. Oleh karena itu, identifikasi pelayananan informasi, manfaat EDMS dan tantangannya harus dipertimbangkan bersama-sama. Ini mendukung pandangan dalam survei literatur, bahwa strategi bisnis harus diintegrasikan dengan IT sehingga EDMS benarbenar akan mencerminkan kebutuhan dan penyedia layanan informasi melalui dokumen elektronik bagi penggunanya (Robson, 2010 dalam Jones, 2012:398).

Penggunaan teknologi EDMS memberikan peluang bagi suatu organisasi untuk memiliki potensi besar dalam mengatasi berbagai tantangan yang berkaitan dengan pengelolaan catatan elektronik dan dokumen-dokumen (Jones, 2008:53). EDMS memiliki peluang dan tantangannya tersendiri sesuai dengan lembaga penggunanya baik dalam dunia pendidikan, pemerintahan dan dunia usaha yang akan dirangkum sebagai berikut:

\section{Dunia Pendidikan}

Sistem pengelolaan dokumen elektronik sangat penting dalam dunia informasi saat ini terutama dalam dunia pendidikan karena implementasi EDMS dalam dunia pendidikan berpeluang meningkatkan kualitas proses pendidikan, penyederhanaan sistem pembelajaran siswa dan guru, kemudahan akses informasi yang dapat diakses siswa, guru, dan orang tua kapan saja dan dimana saja, memudahkan staf atau pekerjanya dalam menyederhanakan penyimpanan dan penggunaan dokumen dalam mengefisiensikan waktu dan tenaganya dibandingkan dengan sistem manual berbasis kertas (paper based) baik dokumen perpustakaan, publikasi ilmiah dan literatur pendidikan akan menjadi sangat relevan dan teratur dalam pengelolaannya meskipun dalam jumlah yang sangat banyak, dan juga efisiensi peralihan dari kertas ke digital elektronik sehingga mengurangi penggunaan kertas yang berlebihan. Hal ini sesuai dengan peneltian yang dilakukan oleh(Ghani et al., 2012; Pechnikova \&A.V.Pechnikova, 1999: Staley and Malenfant, 2010; Wokocha and Adebayo, 2012; dalam Krasnyanskiy, Ostroukh, Molotkova, \& Galygina, 2014:184) yang lebih pro terhadap implementasi EDMS dalam dunia pendidikan yang berpeluang memberikan banyak manfaat 
sesuai dengan penggunaannya.

Beberapa hambatan dan tantangan dalam mengimplementasikan EDMS berdasarkan hasil wawancara menunjukkan masih banyak staf atau pekerja menggunakan sistem tradisional atau sistem manual berbasis kertas (paper based) dalam mengelolah dokumennya karena merasa sudah terbiasa dan merasa nyaman seperti yang dilakukan selama ini, selain itu, kurangnya pengetahuan dan pemahaman staff pekerja akan pentingnya penggunaan EDMS, beberapa staff juga merasa kesulitan dalam menerapkan EDMS, selain itu, keengganan yang dirasakan staf atau pekerja senior untuk belajar hal yang baru tentang EMDS kepada Staf atau pekerja yang lebih junior dan lebih memahami EDMS. Contohnya adalah banyak pustakawan dan arsiparis senior di Afrika yang secara psikologi memiliki fobia terhadap perkembangan teknologi karena mereka merasa harus belajar hal baru kembali bersama mereka yang lebih muda dan sebagai akibatnya, menjadi merasa terancam dan tidak lagi merasa menjadi expert (Asogwa, 2012:202 dalam Putranto, 2017:6). Oleh karena itu, sesuai dengan kebutuhannya untuk meningkatkan keandalan dan dokumen yang tersimpan dalam database dokumen yang luas membutuhkan pendekatan sistematis yang diberikan secara spesifik dalam dunia pendidikan (Novikov \& Sukhanow, 2005:80).

\section{Dunia pemerintahan}

Implementasi sistem manajemen dokumen dalam lembaga pemerintah berpeluang untuk memberikan layanan kepada masyarakat secara efektif, efisien dan transparan, hal ini sesuai dengan pendapat (Gershon, 2004 dalam Jones,
2012:396) yang menyatakan bahwa penerapan teknologi baru dapat dimanfaatkan untuk mentransformasikan penyampaian layanan pemerintah kepada masyarakat. Beberapa studi literatur penelitian e-Government menyatakan bahwa manfaat aspek teknologi dalam sistem manajemen dokumen elektronik sebagai pelayanan jasa di lembaga pemerintah yang fokus padateknologi pencarian dokumen elektronik yaitu kemudahan akses dokumen bagi penggunanya melalui teknologi dokumen elektronik berbasis multimedia yang didukung dan didentifikasi dalam multi bahasa sesuai dengan bahasa yang diinginkan (Baker, Sircar, \& Schkade, 1998; Huang, 2003; Motta, Shum, \& Domingue, 2000; Prager, 1999 dalam Hung, S. Y., Tang, K. Z., Chang, C. M., \& Ke, C. D., 2009:387). Penelitian (Mullner \& Grimm, 2004:469; Steyaert,2004:474)juga menyatakan bahwa pengarsipan dokumen elektronik secara online melalui teknologi e-Governmentyang dibarengi dengan perbaikan teknologi EDMS sangat penting karena lebih praktis atau tidak ribet dan tidak perlu antrian panjang serta memudahkan dalam memberikan pelayanan di lembaga pemerintahan.

Laporan pemerintah dari Kantor Kabinet (2005, 2007) bersama dengan literatur (Hackney et al., 2008; Irani \& Elliman, 2008:6) menyatakan bahwa sektor publik harus lebih inovatif dan mengenalkan lebih banyak sistem pelayanan digital dengan memanfaatkan kecanggihan teknologi saat ini, dan memperbaiki arus elektronik dalam memberikan informasi secara akurat kepada warga negaranya. Hal ini sesuai dengan (Jones, 2012:396) yang menyatakan bahwa dalam upaya meningkatkan 
pelayanan jasa baik secara internal bagi lembaga pemerintah maupun eksternal bagi warga negara perlu memanfaatkan lebih banyak teknologi inovatif dengan menerapkan sistem IT.

Dalam rangka meningkatkan efektivitas kolaborasi antar pemerintah di beberapa negara juga menunjukkan bahwa pemerintah telah banyak berinvestasi dalam menerapkan pelayanan e-Government untuk meningkatkan kualitas pelayanan jasanya (West, 2007:1). Di Amerika Serikat, praktik EDMS menjadi semakin banyak dijadikan objek penelitian dalam beberapa tahun terakhir (Cornwell et al., 1993:122; Leighton, 1992:279; Yang \& da Conturbia, 1998) akan tetapi dalam tantangannya menunjukkan bahwa partisipasi dalam akses elektronik ke program dokumen negara tetap rendah. Sebagai contoh Pelayanan $e$ Government di lembaga pemerintahan Taiwan telah diakui dan banyak mendapat pujian namun tingkat persetujuan dalam hal e-Government melalui EDMS juga masih rendah karena kurangnya pemahaman dan pengetahuan pentignya EDMS(Hung, Chang, \& Yu, 2006:98). Oleh karena itu, dalam mengimplemntasikan EDMS agar berpeluang memberikan banyak manfaat yang dirasakan bagi penggunanya maka lembaga pemerintah di beberapa negara perlu mengidentifikasi faktor penentu persetujuan implementasi EDMS untuk meningkatkan kinerja pelayanan jasa melalui e-Government dalam lembaga pemerintahan.

\section{Dunia Usaha}

Dunia usaha EDMS memberikan banyak manfaat dalam penggunaannya sebagai elemen penting dalam meningkatkan usahanya. Proses implementasi dokumen menggunakan perangkat lunak elektronik dan EDRM merupakan suatu produk yang berdiri sendiri atau bagian dari sistem perusahaan yang lebih besar (Joseph, 2016:22). Penggunaan EDMS telah digembargemborkan sebagai solusi untuk berbagai masalah organisasi dan perusahaan bisnis (Adam, 2007:42). Salah satunya adalah bagi staf yang menghadapi banyak pelanggan dan klien, penting bagi mereka untuk dapat mengakses semua dokumen informasi yang berkaitan dengan pelanggan dan kliennya secara akurat demi kelancaran usahanya, maka untuk dapat mengakses semua informasi tersebut secara cepat mereka dapat mengakses secara elektronik dengan memanfaatkan EDMS(Jones, 2012:397). Selain itu juga banyak potensi penghematan waktu dan tenaga kerja, mempermudah pekerjaan, melindungi investasi yang dapat diakses melalui dokumen elektronik yang dibuat berdasarkan standar perusahaan, memungkinkan jejak audit dan memastikan akuntabilitas (Hjelt \& Björk, 2006:113). Pendukung EDMS juga menyatakan bahwa implementasi EDMS dapat menyelesaikan masalah-masalah bisnis yang kompleks, memberikan keuntungan secara kompetitif bagi perusahaanya dan memudahkan perusahaan dalam mengakses informasi perkembangan usahanya (Hammer \& Hershman, 2010 dalam Jones, 2012:396).

Penggunaan dokumen elektronikyang berisi banyak komponen informasi yang berhargasecara efisien berdampak banyak anggota virtual enterprises (VE) yang merupakan aliansi dari beberapa perusahaan yang bekerjasama untuk lebih merespon peluang bisnis yang didukung oleh jaringan komputer 
untuk dapat meningkatkan efisiensi kerjanya melalui EDMS yang dirancang dalam beberapa tahun terakhir, misalnya perangkat lunak Master Control, modul kontrol dokumen QMS/9000+, sistem Pengendalian Dokumen dan iSO-Pro sistem perangkat lunak (Yao \& Trappey, 2001:355). Sebagai contoh, pertimbangan dalam UK Local Authority (UKLA) yang baru-baru ini dilakukan dalam berbagai perusahaan maupun organisasi telah menerapkan EDMS (Jones, 2012:396).

Dapat disimpulkan bahwa implementasi EDMS memberikan peluang dan tantangannya tersendiri. Di satu sisi, mempermudah penggunanya dalam memberikan akses informasi dalam menemukan dan mengakses dokumen yang mereka inginkan, implementasi EDMS berpeluang dapat mengubah budaya kerja dan cara kerja sebuah organisasi dalam melakukan pekerjaannya, yaitu dengan bekerja di rumah atau melalui mobile ponsel seseorang dapat mencari dokumen yang diperlukan kapan saja dan dimana saja tanpa perlu antri panjang menghabiskan waktu dan tenaga, kemudahan dalam menyelesaikan pekerjaan secara elektronik serta keandalan data dan manajemen proses kerja yang lebih baik, serta memberikan sistem informasi yang koheren yang dapat melintasi area geografi dan beberapa situs organisasi yang memiliki tujuan utama untuk memperbaiki arus informasi, pengaturan kerja dan efisiensi organisasi, selain itu, kontrol dan manajemen dokumen menjadi lebih baik, efisiensi yang lebih besar dalam menjaga, mengakses, dan mendistribusikan dokumen yang diperlukan.

Implementasi EDMS juga memiliki tantangannya yaitu EDMS tidak didasarkan pada studi kelayakan biaya formal. Dalam penggunaan EDMS membutuhkan biaya yang cukup besar mulai dari pengadaan alatnya, perawatannya, pelatihan dan sosialisasi bagi staf pengelolanya. Hal ini sesuai dengan (Reed, 2010:125 dalam Putranto, 2017:5) menyatakanbahwa implementasi dokumen elektronik memerlukan biaya pembelian software, lisensi ataupun perawatan yang kerap kali menimbulkan keengganan karena dianggap terlalu mahal. Selain itu, kebanyakan perusahaan kecil juga dituntut untuk dapat mengadopsi sistem EDMS yang sama seperti yang digunakan oleh perusahaan besar yang mereka tangani untuk mengelola keseluruhan proyek (Forcada, 2005:49). Tantangan yang banyak dihadapi institusi dalam pengelolaan arsip elektronik seperti keamaan dan privasi, resiko kehilangan data, isu otentisitas, sumber daya manusia dan infrastruktur ataupun kebutuhan pengelolaan secara umum (Asogwa, 2012:205 dalam Putranto, 2017:5). Dinamika sumber daya manusia juga menjadi salah satu hal penting yang memiliki dampak pada isu teknis maupun kebijakan, sebagai contoh penelitian (Harries, 2009:18 dalam Putranto, 2017:5) menyebut ketidakmampuan mengoperasikan sistem ataupun kehilangan dokumen elektronik juga masih terus berlangsung. Tantangan lainnya adalah penerapan sistem IT semakin dianggap inovasi yang kurang bersifat sosial, risiko penerapan EDMS yang tidak berhasil akan mempengaruhi potensi organisasi di masa depan (Irani, 2010:217).

Oleh karena itu, agar dapat meminimalisir hambatan dan tantangan dalam meng- 
implementasikan penggunaan EDMS maka beberapa hal yang perlu diperhatikan dan dilakukan adalah sebagai berikut:

1) Pertama, setiap organisasi yang menggunakan EDMS harus mendukung dan mengembangkan strategi yang tepat bersamaan dengan dukungan internal organisasi sesuai dengan kebutuhan penggunaan EDMS. Beberapa hal yang perlu diperhatikan adalah perencanaan, pengelolaan dan pemantauan untuk memastikan penggunaan, nilai dan manfaat terbaik yang diperoleh dalam bidang teknologi untuk meningkatkan kinerja pelayanan dalam memberikan informasi secara efektif, efisien, akurat, dan transparan;

2) Kedua, bahwa studi kelayakan yang tepat harus dilakukan secara berkala yang mengidentifikasi biaya yang dikeluarkan, nilai dan manfaat dari implementasi EDMS yang dirasakan.Ini akan memungkinkan organisasi memahami dampak positif dan negatif dari penggunaan EDMS;

3) Ketiga, pelatihan dan pendidikan serta sosialisasi yang perlu dilakukan agar semua staf yang bekerja dalam bidang pengelolaan dokumen dapat memahami, terampil dan memiliki pengetahuan yang baik dalam menggunakan teknologi EDMS yang berorientasi pada kinerjanya;

4) Keempat, dukungan yang tepat dari pihak internal lembaga baik pimpinan, staf pengelola dokumen, dan tim IT untuk membantu memastikan bahwa pelaksanaan teknis EDMS dapat berhasil. Hal ini karena implementasi EDMS tidak sepenuhnya cepat selesai, memerlukan beberapa proses dan proses tersebut perlu dikembangkan dan diidentifikasi secara berkelanjutan;

5) Kelima, strategi manajemen dokumen perlu dikembangkan untuk memastikan dokumen elektronik diproses, disimpan dan dimusnakan dengan tepat. Strategi pencetakan perlu dikembangkan untuk meminimalkan jumlah pencetakan dan jumlah printer yang digunakan, hal ini akan mengurangi biaya yang ada;

6) Keenam, sistem keamanan dokumen yang kuat harus diperhatikan agar keamanan dokumen dalam EDMS dapat terjaga dengan baik; dan

7) Terakhir, proses pengawasan, pemantauan, review dan evaluasi pasca implementasi harus dilakukan untuk memastikan bahwa implementasi berhasil atau tidak serta mengidentifikasi hambatan atau tantangan yang mungkin terjadi sebagai tindakan perbaikan yang harus dilakukan secara sistematis.

\section{KESIMPULAN}

Implementasi EDMS memiliki dampak positif dan negatif bagi suatu organisasi atau lembaga penggunanya. Meskipun implementasi EDMS dalam beberapa literature penelitian memiliki hasil yang beragam yang menunjukan pro dan kontra serta beberapa tantangan atau hambatan dalam penggunaanya, implementasi EDMS perlu dipertimbangkan bagi suatu organisasi atau lembaga tertentu baik sektor publik dan swasta. Hal ini untuk meningkatkan kualitas pelayanan informasi secara efektif, efisien, akurat dan transparan sesuai dengan 
tuntutan kemajuan teknologi sekarang yang membutuhkan informasi secara cepat yang dapat diakses kapan saja dan dimana saja sesuai dengan kebutuhannya. Agar dapat meminimalkan hambatan dan tantangan dalam mengimplementasikan EDMS maka beberapa hal yang perlu diperhatikan dan dilakukan adalah perlu adanya dukungan dari berbagai pihak internal maupun eksternal yang terlibat dalam suatu organisasi, diperlukan kerjasama antara pihak yang terkait, perlunya pengadaan pelatihan, pendidikan dan sosialisasi tentang pentingnya EDMS, perlu adanya studi kelayakan tentang biaya, nilai dan manfaat EDMS, institusi perlu memiliki strategi manajemen dokumen apakah disimpan atau dimusnahkan, serta pengawasan, pemantauan, evaluasi dan juga tindakan perbaikan yang dilakukan secara sistematis dan berkala.

\section{DAFTAR PUSTAKA}

Adam, A. 2007. Implementing electronic document and record management systems. New York: Auerbach Publications.

Asogwa, B. E. 2012. The challenge of managing electronic records in developing countries: Implications for records managers in sub Saharan Africa. in Records Management Journal 22(3): 198-211. https://doi.org/ $10.1108 / 09565691211283156$

Baker, J. H., Sircar, S., \& Schkade, L. L. 1998. Complex document search for decision making. Information \& Management 34(4): 243-250. https://doi.org/10.1016/S03787206(98)00061-5

Cornwell, G., Kessler, R. R., Aldrich, D., Andersen, T. K., Hayes, S. M., Sulzer, J., \& Tulis, S. 1993. Problems and issues affecting the United-States depository library program and the GPO-the librarians manifesto. Government Publications Review 20(2): 121-140. https://doi.org/10.1016/02779390(93)90106-Y

Finney, J. 1999. Software can help reduce ISO non-conformances. Midrange ERP.46-48.

Forcada, N. 2005. Life cycle document management system for construction. Doctoral Thesis. Technical University of Catalonia: Department of Construction Engineering.

Ghani, E. K., Muhammad, K., \& Said, J. 2012. Development of integrated information management system service quality model in an accounting faculty. Interntional Journal Bussines Social Sci 3:245-252.

Gregory, K. 2005. Implementing an electronic records management system: A public sector case study. In Records Management Journal 15(2): 80-85. https://doi.org/10.1108/ 09565690510614229

Gershon, S. P. 2004. Independent review of public sector efficiency: releasing resources to the front line. London: HM Treasury.

Groenewald, T. 2004. Electronic Document Management: A Human Resource Management Case Study. SA Journal of Human Resource Management 2(1): 54-62.

Hackney, R., Desouza, K. C., \& Chau, P. 2008. Editorial: eGovernment strategies: ICT innovation in international public sector contexts. Journal of Strategic Information Systems 17(2): 73-74.

Hammer, M., \& Hershman, L. W. 2010. Faster, cheaper, better: The 9 levers for transforming how work gets done. New York: Tantor Media, Inc.

Harries, S. 2009. Managing records, making knowledge and good governance. In Records Management Journal 19(1): 16-25. https://doi.org/10.1108/0956569091093721 8

Hjelt, M., \& Björk, B.-C. (2006). Experiences of EDM Usage in Construction Projects, Special issue e-Commerce in construction 
11:113-125. https://doi.org/10.1.1.212.1192

Huang, A. H. (2003). Effects of multimedia on document browsing and navigation: An exploratory empirical investigation. Information \& Management 41(2): 189-198. https://doi.org/10.1016/S03787206(03)00047-8

Hung, S. Y., Chang, C. M., \& Yu, T. J. (2006). Determinants of user acceptance of the eGovernment services: The case of online tax filing and payment system. Government Information Quarterly 23(1): 97-122. https://doi.org/10.1016/j.giq.2005.11.005

Hung, S. Y., Tang, K. Z., Chang, C. M., \& Ke, C. D. $(2009)$. User acceptance of intergovernment serices: An Examples management system. Government Information Quarterly 26: 387-397. https://doi.org/10.1016/j.giq.2008.07.003

Irani, Z. (2010). Investment evaluation within project management: an information systems perspective. Journal of the Operational Research Society 61(6): 917-928. https://doi.org/10.1057/ jors. 2010.10

Irani, Z., \& Elliman, T. (2008). Creating social entrepreneurship in local government. European Journal of Information Systems. 1-7.https://doi.org/10.1057/ejis.2008.35

ISO9001. (2015). Quality systems-model for quality assurance in design, development, production, installation, and service. ANSI/ISO/ASQC.

ISO9004. (2016). Quality management and quality system elements-guidelines. ANSI/ISO/ASQC.

Johnston, G. P., \& Bowen, D. V. (2005). The Benefits of Electronic Records Management Systems: A General Review of Published and Some Unpublished Cases. Records Management Journal 15(3): 131-140. https://doi.org/10.1108/0956569051063231
9

Jones, P. (2008). The role of virtual folders in developing an electronic document and records Meeting user and records management needs. Records Management Journal 18(1): 53-60. https://doi.org/ $10.1108 / 09565690810858514$

Jones, S. (2012). eGovernment Document Management System : A case analysis of risk and reward. International Journal of Information Management 32: 396-400. https://doi.org/10.1016/j.ijinfomgt.2012.04. 002

Joseph, P. I. P. (2016). User difficulties working with a business classification scheme : a case study. Records Management Journal 26(1): 21-37. https://doi.org/10.1108/RMJ-032015-0011

Krasnyanskiy, M. N., Ostroukh, A. V., Molotkova, N. V., \& Galygina, I. V. (2014). Electronik Document Management Systems for University Research and education. Journal Engineering Ang Applied Science 9(5): 182-189.

Leighton, H. V. (1992). Electronic availability lists for United-States federal document depository libraries-opportunities and realities. Government Publications Review 19(3): 279-287. https://doi.org/10.1016/ 0277-9390(92)90067-L

Motta, E., Shum, S. B., \& Domingue, J. (2000). Ontology-driven document enrichment: principles, tools and applications. International Journal Human-Computer Studies 52: 1071-1109. https://doi.org/ 10.1006/ijhc.2000.0384

Mullner, T., \& Grimm, D. (2004). Applications and interface for e-Government. Proceedings of the Electronic Government Conference.472-475.

Novikov, D.A., \& Sukhanow, A. (2005). Models and management mechanisms research 
projects universities. Education Management Institute of Atthe Russian Academy of Sciences, Moscow, (In Russian).

Pechnikova, T. V., \& A. V. Pechnikova, 1999. The practice of workin. (1999). The practice of working with documents in the organization. EMOS Moscow 208. (In Russian).

Prager, J. M. (1999). Linguini: Language Identification for Multilingual Documents. Journal of Management Information Systems 16(3): 71-101. https://doi.org/ 10.1080/07421222.1999.11518257

Putranto, W. A. 2017. Pengelolaan Arsip di Era Digital: Mempertimbangkan Kembali Sudut Pandang Pengguna. Diplomatika. 1 (1):1-11. https://doi.org/10.22146/diplomatika.28253

Read, M. (2009). Back office operations and IT, operational efficiency programme final report. London: HM Treasury.

Reed, B. (2010). Service-oriented architectures and recordkeeping. in Records Management Journal 20(1): 124-137. https://doi.org/ $10.1108 / 09565691011039898$

Remenyi, D., Bannister, F., \& Money, A. (2007). The effective measurement \& management of IT costs \& benefits. ButterworthHeinemann.

Robson, W. (2010). Strategic management \& information systems. United Kingdom(UK): Pitman Publishing.

Simonds, B. (2008). ICON Portal's Document Management System. Military Intelligence Professional Bulletin 34(1): 22-24.

Sladić, G., Cverdelj-Fogaraši, I., Gostojić, S., Savić, G., Segedinac, M., \& Zarić, M. (2017). Multilayer document model for semantic document management services. Journal of Documentation 73(5): 803-824. https://doi.org/10.1108/JD-07-2016-0095

Sprague. RH 1995. Electronic Document Management: Challenges and Opportunities for Information Systems Managers. MIS Quarterly, Vol. 19, No. 1 (Mar., 1995), pp. 29-49

Staley, D. J., \& Malenfant, K. J. (2010). Futures thinking for academic librarians: Higher education in 2025. Information Service Use 30: 57-90. https://doi.org/10.3233/ISU2010-0614

Steyaert, J. C. (2004). Measuring the performance of electronic government services. Information \& Management 41(3): 369-375. https://doi.org/10.1007/978-981$10-2176-3$

West, D. M. (2007). Global e-Government full report, 2006. Center for Public Policy: Brown University. Retrieved from http://www.insidepolitics.org/ egovt07int.pdf, 2007.

Wilkins, L., Swatman, P. M. C., \&Holt, D. (2009). Achieved and tangible benefits: lessons learned from a landmark EDRMS implementation. Records Management Journal 19(1): 37-53. https://doi.org/ 10.1108/09565690910937236.

Wokocha, C. M., \& Adebayo, E. I. (2012). A guide to establishing management information system in tertiary institutions in Nigeria. Africa Journal Basic Applied Sci 4: 83-8.

Yang, Z. Y., \& da Conturbia, S. (1998). US state documents in academic libraries. Journal of Government Information 25(3): 263-276. https://doi.org/10.1016/S13520237(98)00007-0

Yao, Y.H., \& Trappey, A. J. C., \& Ho. P. S. (2003). XML-based ISO9000 electronic document management system. Robotics and Computer Integrated Manufacturing 19: 355-370. https://doi.org/10.1016/S07365845(03)00003-6

Zantout, H., \& Marir, F. (1999). Document management systems from current capabilities towards intelligent information retrieval: an overview. International Journal of Information Management 19(6); 471-484. https://doi.org/10.1016/S02684012(99)00043-2 